\title{
Some Problems of the Integration of Heat Pump Technology into a System of Combined Heat and Electricity Production
}

\author{
G. Böszörményi, L. Böszörményi
}

The closure of a part of the municipal combined heat and power (CHP) plant of Košice city would result in the loss of $200 \mathrm{MW}$ thermal output within a realtively short period of time. The long term development plan for the Košice district heating system concentrates on solving this problem. Taking into account the extremely high (90\%) dependence of Slovakia on imported energy sources and the desirability of reducing the emission of pollutantst the alternative of supplying of $100 \mathrm{MW}$ thermal output from geothermal sources is attractive. However the indices of economic efficiency for this alternative are unsatisfactory. Cogeneration of electricity and heat in a CHP plant, the most efficient way of supplying heat to Košice at the present time. If as planned, geothermal heat is fed directly into the district heating network the efficiency would be greatly reduced. An excellent solution of this problem would be a new conception, preferring the utilization of geothermal heat in support of a combined electricity and heat production process. The efficiency of geothermal energy utilization could be increased through a special heat pump. This paper deals with several aspects of the design of a heat pump to be integrated into the system of the CHP plant.

Keywords: geothermal energy, ejector, heat pump.

\section{Introduction}

As a result of illogical trends in power prices, the competitiveness of district heating has greatly decreased in recent years in Košice. This situation is aggravated by the fact that a part of the heating plant is already reaching the end of its working life. If this part were to be closed, it would result in a shortfall of 200 MW heat output. The long term development plan for the Košice district heating system focuses on solutions to this problem. It also takes into account the demands of the national electricity supply network, and is therefore considering three possibilities. An alternative is needed because of Slovakia's extremely high (90\%) dependence on imported energy sources, and the need for a lower level of the emission of pollutants. It is planned to establish a new gas-steam cycle-based CHP plant-module with a $100 \mathrm{MW}$ thermal output, and to supply $100 \mathrm{MW}$ thermal output from geothermal sources. However the efficiency parameters (net present value, internal rate of return and payback period) indicate that competitiveness of this alternative is rather low.

\section{Current plan for geothermal energy utilization in the district heating system for Košice}

The current plan for geothermal energy utilization is based on direct feeding with this energy into the district heating system. This is justified by its relatively high temperature $\left(115-130{ }^{\circ} \mathrm{C}\right.$ at a depth of about $2000-2500 \mathrm{~m}$ and $130-150^{\circ} \mathrm{C}$ in the depth of about $2500-3000 \mathrm{~m}$ ). According to the plan, nearby villages such as Bidovce, Durkov, Ruskov and Slanec will have two pairs of production and reinjection wells (doublets) and one heat exchanger plant. Thermal water will be pumped into the heat exchanger plants from the production wells. The thermal will infuse its thermal energy into the secondary mains water situated in the heat exchangers, and then the water will be returned to the earth's crust through two reinjection wells. The thermal energy thus acquired will then be transported to the heating plant by the secondary mains water. This will be done with the help of pumping stations, and the CHP plant will enable it to be used in the district heating system. According to the plan, more than $2500 \mathrm{TJ}$ can be obtained this way to supply the town with heat from geothermal energy sources.

\section{More rational utilization of the geothermal energy}

An examination of this conception of geothermal energy leads us to an important and to some extent surprising realization: according to the plan, the temperature of the thermal water compressed back into the reinjection wells should be higher than $60{ }^{\circ} \mathrm{C}$. This means there will be an extremely low degree of exploitation of the available geothermal energy capacity. It seems justified to assume that an increase in the utilization degree would be the most efficient way to improve the economic efficiency parameters. Approximately 9 mil. USD could be saved on investment costs in the case of upgraded utilization of the available goethermal energy capacity. About 70 MW heat output could be gained from direct utilization and about 30 MW from indirect utilization. The indirect utilization stage would be implemented by a heat pumping plant, which would utilize the heat output produced by cooling down the returning secondary mains water by about $20 \mathrm{~K}$ at a higher temperature level. Thus the temperature at which the thermal water is compressed back would decrease to a similar extent. This conception can lead to some 
improvement in the competitiveness of geothermal energy. However the main reason for unsatisfactory economic efficiency (the conflict between cogenerated heat and geothermal heat) cannot be set aside, since this comes from the concept of geothermal energy utilization. Cogeneration of electricity and heat, the bases of the relatively efficient heat supply of the town at a present time be very strongly limited if geothermal energy were to be fed into the district heating network. The conception of integrating geothermal energy sources into a system of combined electricity and heat production in the municipal CHP plant would be an excellent solution to this problem. The principal scheme is illustrated in Fig. 1. In this conception the utilization of geothermal energy in support of a combined electricity and heat production process would be preferred.

The stream of the secondary geothermal energy medium into the CHP plant would be divided into two parts. The higher flow would be used for heating the feed water in the steam cycle. The lower flow would be used directly in the district heating network:

- for domestic heating and hot water in winter period,

- for absorption cooling in the summer period.

After that, the streams would be mixed and cooled down by about $20 \mathrm{~K}$ in a heat pumping plant. The resulting flow of the secondary geothermal energy medium could be used for cooling the condenser in the steam cycle. The advantage of this solution would be that the primary geothermal water would be injected back into the earth's crust at a lower temperature than without using the heat pump. Moreover a part of the energy losses from the condenser would be stored in this water in the earth's crust.

The thermal output of the heat pumping plant could be utilized the following way:

- for domestic heating and hot water in two housing estates near the CHP plant in the winter period,

- for domestic hot water preparing throughout the city in the summer period.
Implementing this conception could reduce investment costs (by about 9 mil. USD) as well as operating costs, and could increase the benefits of geothermal energy utilization in the Košice district heating system.

\section{Selection of the heat pumping technology}

One of main conditions for efficient geothermal energy utilization in this conception is the correct selection of the heat pump technology and its integration into the combined electricity and heat production system.

Heat pumping technology can be classified according to:

- the number of stages of evaporation and condensation the most probable method would be to implement these processes in at least two stages.

- the coolant that is used. Water can be used as a coolant. In addition to water, refrigerants R134a and R717 (ammonia) were analyzed, for lower dew and evaporation temperatures.

- the method of compression. Steam can be compressed mechanically in turbocompressors in two stages, or by thermocompression in an ejector in a single stage. R134a and $\mathrm{R} 717$ vapors can be compressed mechanically in two stages.

This system could work the following way. In summer, all the required heat power ( $\sim 45 \mathrm{MW})$ would be produced by the heat pump. Consequently, the gas-steam cycle would produce mostly electricity. In winter, only one housing estate in Košice city would be supplied with heat power ( $\sim 65 \mathrm{MW})$ by the heat pump. The most of the heat power would be produced in the gas-steam cycle.

One possible solution of the heat pump conception is the three-stage alternative version in Fig. 2. This alternative is a combination of direct (first stage) and indirect (second and third stage) processes of evaporation and condensation. In the first stage, steam is compressed in a one-stage ejector by the motive steam acquired from the steam turbine of the

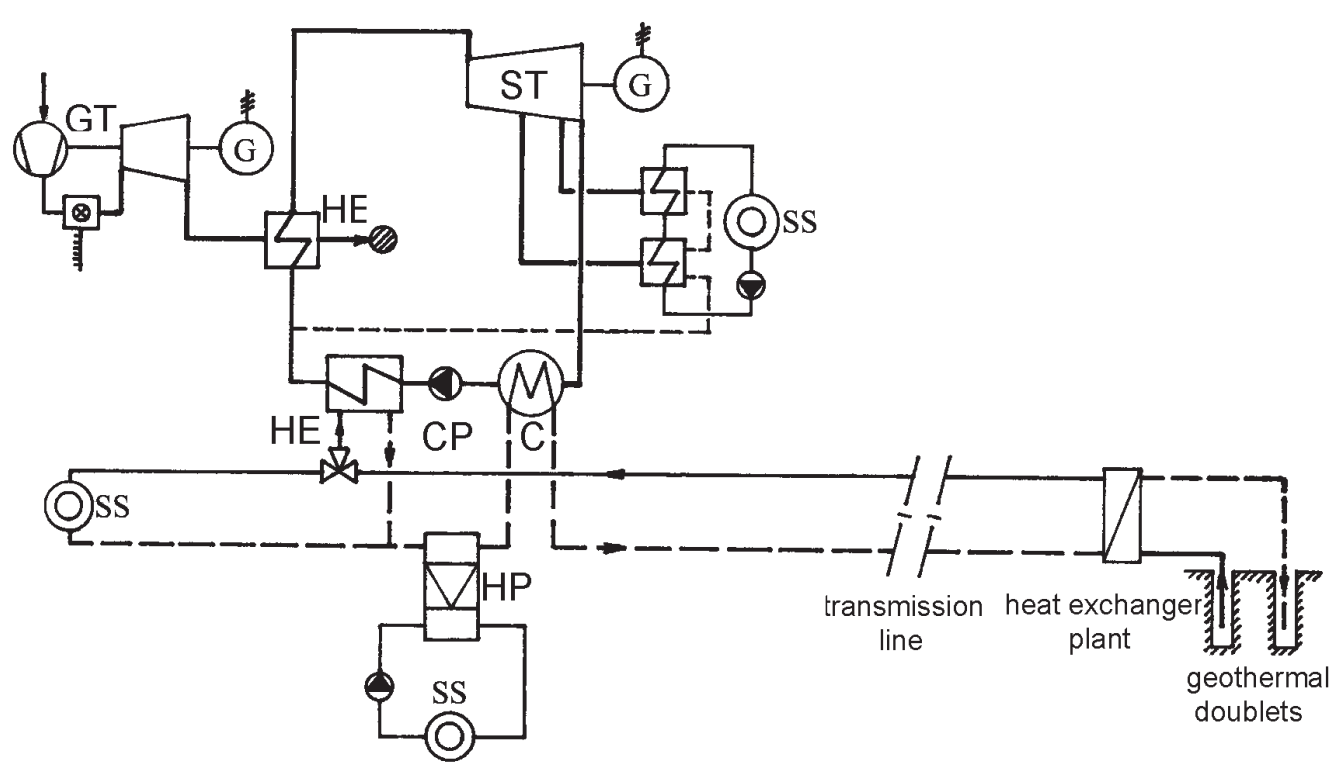

Fig. 1: Scheme of the integration of the geothermal source into the combined heat and electricity production system based on a gas-steam cycle 


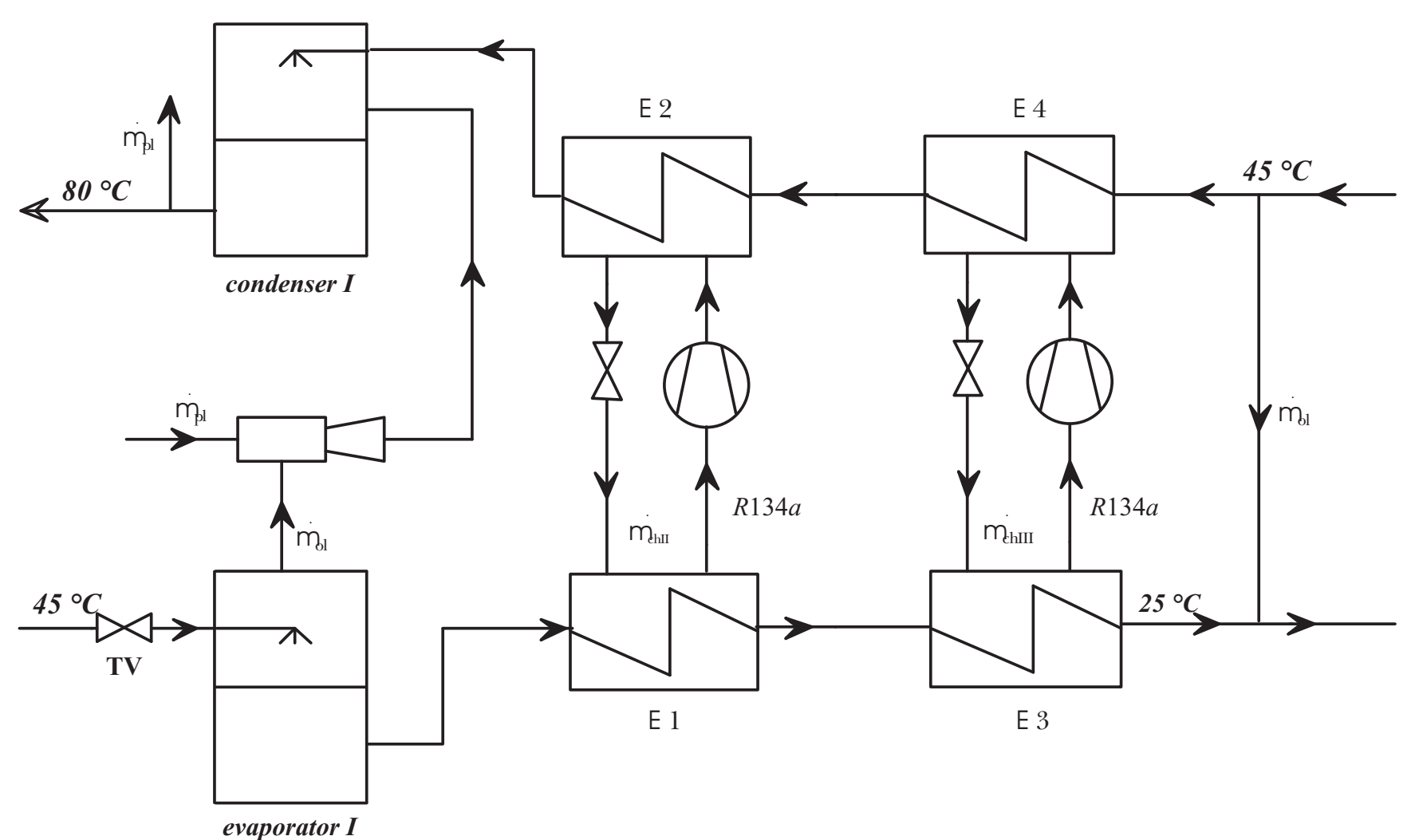

Fig. 2: The three-stage alternative version of the heat pump integrated into combined heat and electricity production using the geothermal source of the Košice basin

gas-steam cycle. The evaporation temperature in the first stage is $39^{\circ} \mathrm{C}$ and the dew temperature is $80^{\circ} \mathrm{C}$. Because of the direct processes in the first stage, the temperature difference in the heat exchangers is negligible. In the second

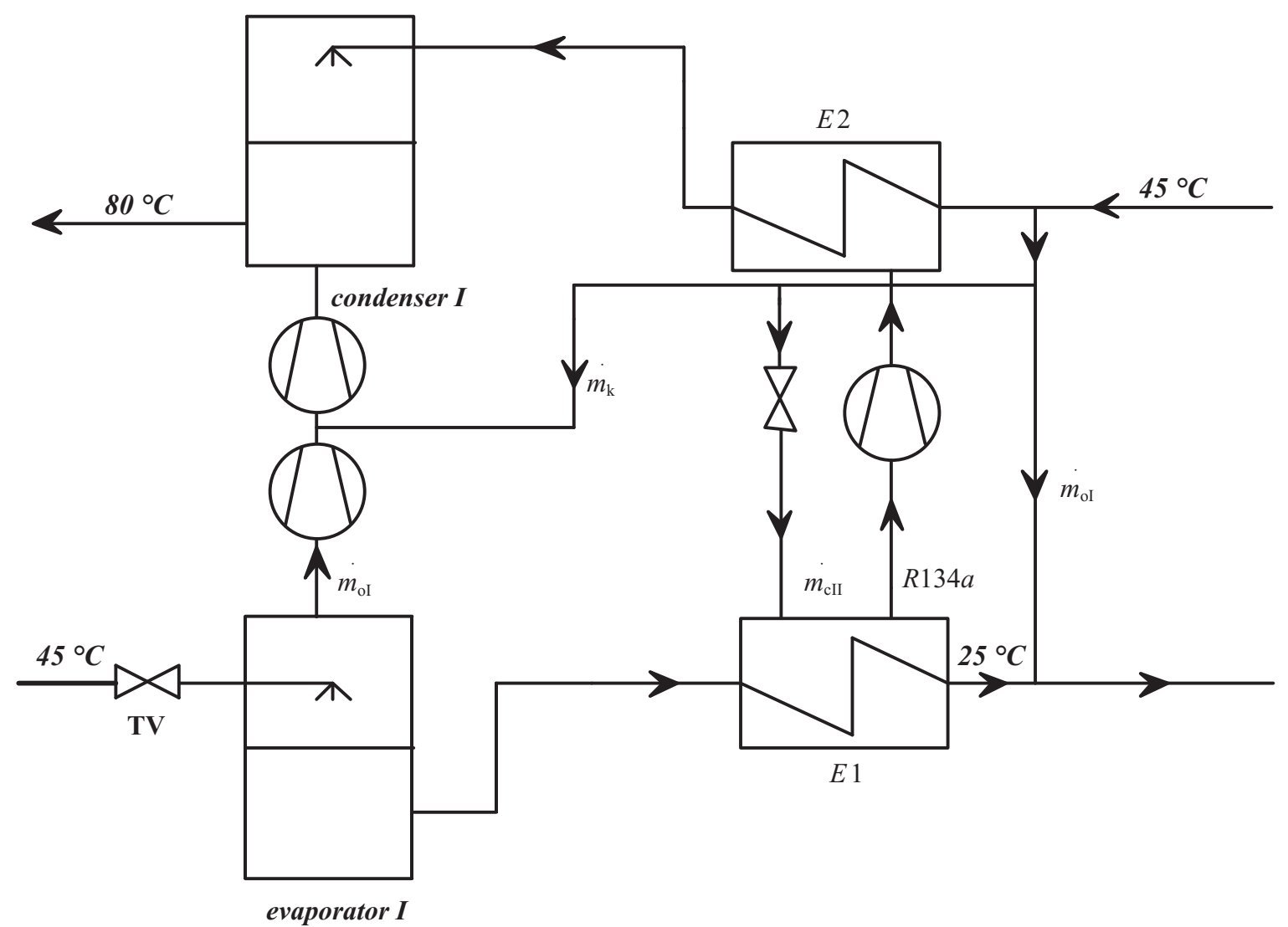

Fig. 3: The two-stage alternative version of the heat pump integrated into combined heat and electricity production using the geothermal source of the Košice basin 
and third stages indirect processes are implemented. In this heat pump, the secondary water is cooled down from $45^{\circ} \mathrm{C}$ to $25^{\circ} \mathrm{C}$ and the water that is used for heating is warmed from $45{ }^{\circ} \mathrm{C}$ to $80{ }^{\circ} \mathrm{C}$. This conception of a heat pump is advantageous due to possibility of heat power regulation. The heat power produced by this alternative is $55 \mathrm{MW}$. The coefficient of performance (COP) is relatively low because of the huge heat power of the motive steam. This energetic valuation does not take into consideration various exergetic qualities of the energies used for vapor compression. This fact could be respected by equal electrical power which is identical to the power we would get from the expansion of the motive steam. Using this assessment the COP reaches significantly higher values.

Another possible solution of the heat pump is the two-stage alternative shown in Fig. 3. Analogous to the previous solution, this version consists of direct processes (in the first stage) and indirect processes (in the second stage) of evaporation and condensation. In the first stage, the steam is compressed mechanically in two stages with intercooling after the intermediate stage. Because of the enormous specific volume of the steam, the process of compression could fake place in axial turbocompressors. In the second stage, vapors of coolant R134a are compressed mechanically. The temperatures of the water cooled down and heated up are as before. In this case the heating power is about $37 \mathrm{MW}$ and the power required for compression is about $7 \mathrm{MW}$. Clearly this variant has a higher COP. However, it has the great disadvantage of problematic steam compression in turbomachinery, resulting from the extremely low partial pressure of steam at low temperatures.

\section{Conclusions}

The three-stage variant has advantageous characteristics both in terms of heat-power regulation and in terms of economic performance. A simplified economic analysis, based on the difference between the selling price of the heat and the cost of providing it, shows the promise of this variant.

It is too early to state that this variant could be the final version of the heat pump technology. It will be necessary to analyze the synergies between the steam turbine of the gas-steam cycle and the heat pump.

\section{List of used symbols}

$\begin{array}{ll}\text { HE, E } & \text { heat exchanger } \\ \text { CP } & \text { condensate pump } \\ \text { HP } & \text { heat pump } \\ \text { C } & \text { condenser } \\ \text { GT } & \text { gas turbine cycle } \\ \text { ST } & \text { steam turbine } \\ \text { G } & \text { generator } \\ \text { SS } & \text { service system } \\ \text { TV } & \text { throttle valve } \\ m & \text { mass flow }\end{array}$

\section{References}

[1] Böszörményi, G.: Využití hydrogeotermálního potenciálu Košické kotliny. Diplomová práce, Praha, 2000

[2] Bussmann, W. (Hrsg.): Geothermie - Wärme aus der Erde. Verlag C. F. Müller GmbH, Karlsruhe, 1991

[3] Austmeyer, K., E.: Mechanical Vapour Recompression. VDI-Society for Energy Technology, Düsseldorf, 1993

\footnotetext{
Ing. Gabriel Böszörményi

e-mail: G.Boszormenyi@sh.cvut.cz

Czech Technical University in Prague

Faculty of Mechanical Engineering

Vaníčkova 5, Koleje Strahov Bl. 6./301

16900 Praha 6, Czech Republic
}

Doc. Ing. Ladislav Böszörményi, CSc.

e-mail: boszla@ccsun.tuke.sk

tel.: +421956024241

fax: +421956321558

Technical University of Košice

Faculty of Civil Engineering

Vysokoškolská 4, 04201 Košice, Slovak Republic 